\title{
Os cuidados paliativos como política pública: notas introdutórias
}

\author{
ANDREA FROSSARD
}

\section{Resumo}

Estudo introdutório sobre cuidados paliativos como política pública sob uma perspectiva materialista histórico-dialética. Disponibiliza-se uma visão panorâmica de dilemas, perspectivas e soluções para a área em questão. Dá-se ênfase à assistência social - parte da seguridade social brasileira - e sua pertinente articulação com a saúde, chamando a atenção para uma área de atuação médica de caráter interdisciplinar, envolta em tabus e quase desconhecida da população brasileira. Pretende-se contribuir com o desenho de programas e ações que visem à melhoria dos cuidados paliativos, especialmente na área oncológica, tanto no que se refere ao sistema e aos serviços de saúde quanto às ações na área de assistência social.

Palavras-chave: Política pública. Seguridade social. Cuidados paliativos.

\section{The Palliative Care as public policy: introductory notes}

\section{Abstract}

Introductory study on palliative care as public policy from a historical and dialectical materialist perspective. It provides a panoramic view of dilemmas, prospects, and solutions for the area concerned. The emphasis lies on social work - a part of the Brazilian social security - and its continued connection to health, drawing attention to a medical practice area that has an interdisciplinary nature, wrapped in taboos and almost unknown to the Brazilian population. It is intended to contribute to design programs nd actions aimed at improving palliative care, particularly in oncology, both in relation to the health system and services and to actions in the social work area.

Keywords: Public policy. Social security. Palliative care.

\section{Los cuidados paliativos como una política pública: notas introductorias}

\section{Resumen}

Estudio introductorio acerca de cuidados paliativos como política pública desde una perspectiva materialista histórica y dialéctica. Se proporciona una visión panorámica de dilemas, perspectivas y soluciones para el área en cuestión. Se hace hincapié en la asistencia social - una parte de la seguridad social brasileña - y su conexión pertinente con la salud, llamando la atención sobre un área de práctica médica con un carácter interdisciplinario, envuelta en tabúes y casi desconocida de la población brasileña. La intención es contribuir al diseño de programas y acciones dirigidas a mejorar los cuidados paliativos, especialmente en oncología, tanto con relación al sistema y los servicios de salud como las acciones en el área de asistencia social.

Palabras clave: Política pública. Seguridad social. Cuidados paliativos. 


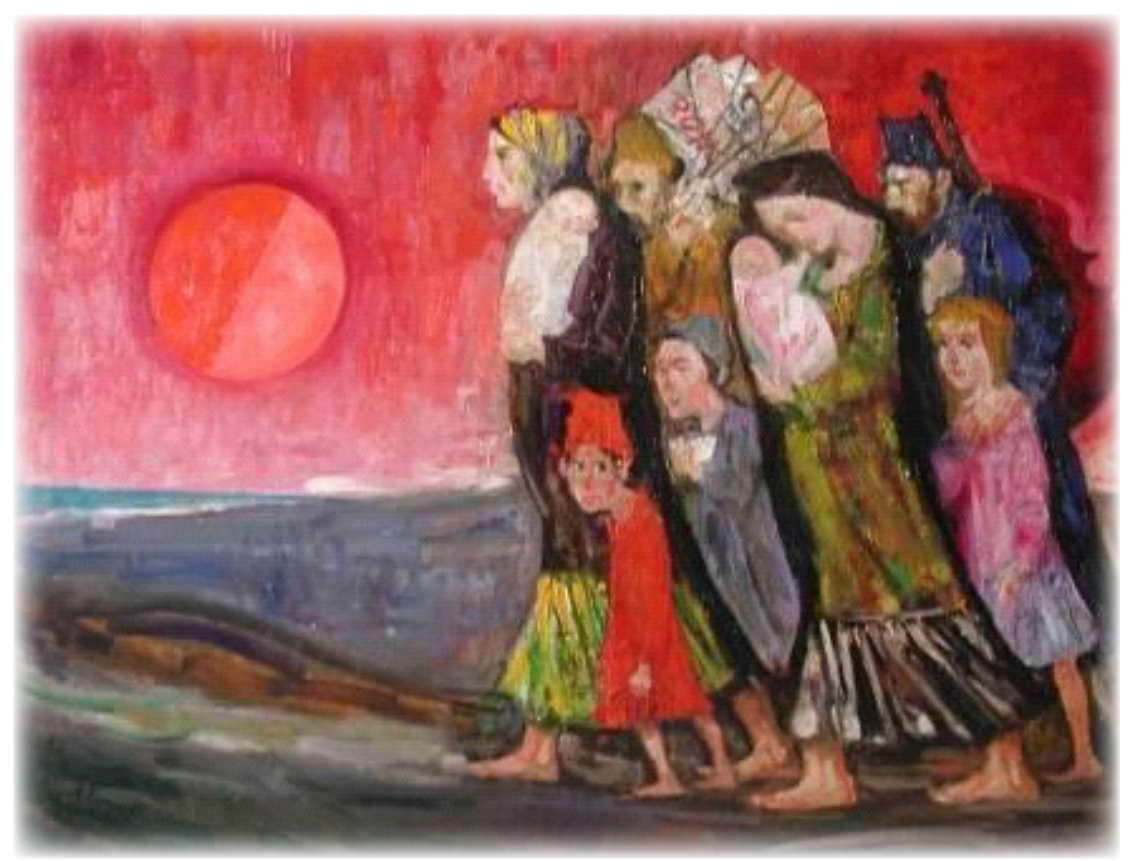

\section{INTRODUÇÃO}

Entende-se por Cuidado Paliativo (OMS, 2002) uma abordagem que defende a qualidade de vida de pacientes - e de seus familiares - com doença que ameaça a continuidade da vida, por meio da prevenção e alívio do sofrimento. Para tanto, requer identificação precoce, avaliação e tratamento da dor e outros problemas de natureza física, psicossocial e espiritual.

Estatísticas divulgadas em 2012 pela Worldwide Palliative Care Alliance mostram que cerca de 18 milhões de pessoas morreram no planeta sofrendo dor desnecessária devido ao acesso inadequado a tratamento de dor. Os Cuidados Paliativos no país se iniciaram nos anos 80 e a Medicina Paliativa veio a se tornar uma área de atuação médica reconhecida em 2011. A qualidade de vida e o alívio de sintomas são primordiais neste âmbito.

De acordo com a literatura corrente (EMANUELL e EMANUEL, 1998; SEILD e ZANNON, 2004), o conceito de qualidade de vida tem origem nas ciências humanas e biológicas com o propósito de valorar o controle de sintomas e o aumento da expectativa de vida. Em relação ao oferecimento da chamada boa morte (MENEZES, 2004), o termo está associado aos cuidados de fim de vida, quando devem ser observados determinados componentes, quais sejam: morte sem dor; morte com os desejos do paciente respeitados; morte em domicílio junto aos familiares e/ou amigos; inexistência de sofrimento por parte do paciente, a quem se deve proporcionar o máximo de sensação de conforto; nos cuidados espirituais e emocionais dos pacientes (ver o núcleo temático: 0 modelo de atenção à saúde: os Cuidados Paliativos, o quadro 1 demonstrativo das principais características do modelo de atenção à saúde em Cuidados Paliativos).

Sabe-se que hoje a política de assistência social não provê os Cuidados Paliativos e, por isso, apresentar essa discussão possibilita abrir uma janela estratégica para o desenho de um programa que os contemplem.

A Constituição de 1988 definiu um novo pacto federativo que gerou mudanças: transferiu a capacidade decisória, de atribuições e de recursos para os estados e os municípios. Ainda hoje, a Carta é criticada porque impossibilita o financiamento de todos os bens e serviços garantidos como direitos universais. Evidentemente, uma sociedade mais solidária está mais disposta a proporcionar o suporte financeiro necessário para a garantia dos mínimos sociais a seus cidadãos.

* Fonte da imagem: Arte de Trento Longaretti. 
Sem dúvida, o campo da assistência social no país é um dos mais requisitados e com transformação em curso. Atravessa um período entendido como filantropia e benemerência até alçar a condição de um direito social inscrito no âmbito da seguridade social brasileira.

Faz-se notório que a assistência em sua trajetória em solo brasileiro se apresentou mais como uma prática personalista e patrimonial e menos como política pública. Há um devir-assistência social por meio de sua inscrição na Constituição Federal de 1988 como um direito social e o seu uso efetivo pelo cidadão como um direito (CARVALHO, 1997; PEREIRA, 1996).

Diante do exposto anteriormente, compreende-se que na abordagem dos Cuidados Paliativos é imprescindível ultrapassar uma visão restrita à cura da doença, direcionando ações que visem à proteção social do paciente e resguardem suas decisões autônomas. Desse modo, enfatiza-se a reflexão a respeito da pertinente articulação entre a política de assistência social e a de saúde no âmbito dos Cuidados Paliativos, visando ao amparo às famílias, principalmente aquelas em situação de pobreza (enfrentam dificuldades no acesso aos serviços e no processo de tratamento).

No decorrer da pesquisa, optou-se pela análise de conteúdo, que propiciou a definição dos núcleos temáticos significativos descritos no decorrer do artigo, a saber: o modelo de atenção à saúde: os Cuidados Paliativos, acessibilidade e Cuidados Paliativos e a humanização e Cuidados Paliativos.

Os núcleos possibilitaram a apresentação panorâmica sobre dilemas, perspectivas e soluções para a área em questão. Além disso, com o apoio analítico do modelo teórico do ciclo de políticas públicas se enfatiza a necessária organização da Rede Nacional de Cuidados Paliativos.

\section{REFERENCIAL TEÓRICO-METODOLÓGICO}

Esta investigação teve como motivação essencial a iluminação dos Cuidados Paliativos no Brasil, com ênfase no campo oncológico, e como base o desenvolvimento da pesquisa estratégica, que se fundamenta nas teorias das ciências sociais e cujo principal objetivo é o esclarecimento de determinados aspectos da realidade para ação das políticas públicas. Seus instrumentos são interdisciplinares e seus resultados apontam para os possíveis caminhos em direção à solução de problemas.

Para Minayo (2011, p. 623),

“O verbo principal da análise qualitativa é compreender. O ser que compreende, compreende na ação e na linguagem e ambas têm como características serem conflituosas e contraditórias pelos efeitos do poder, das relações sociais de produção, das desigualdades sociais e dos interesses. [...] interpretação se funda existencialmente na compreensão e não vice-versa, pois interpretar é elaborar as possibilidades projetadas pelo que é compreendido".

Durante o processo investigativo foi utilizada a pesquisa bibliográfica e telematizada, com apoio em diversas fontes de dados primários e secundários, à luz da teoria crítica de veio marxiano, buscando-se uma interlocução interteórica para apresentar os dilemas, perspectivas e soluções para os Cuidados Paliativos no país.

Considerando o referencial teórico-metodológico marxista, entende-se a realidade como uma totalidade em movimento cuja apreensão se dá em uma relação dialética de idas e vindas numa perspectiva histórica. Assim, compreende-se que as políticas sociais decorrem de uma correlação de forças (econômicas, políticas e sociais) presentes em um determinado momento histórico (FALEIROS, 2009).

Desse modo, a política pública é compreendida em sua inserção num campo de relações contraditórias entre as forças sociais presentes na sociedade e que perpassam o Estado visando ao enfrentamento da questão social.

Para Tanezini (2004, p. 19):

“O lócus das políticas públicas são as instituições que as implementam, ambas são fenômenos da realidade, inseridas na dinâmica das relações sociais, ou seja, são perpassadas pelo embate entre os diversos segmentos sociais e o Estado - e está relacionada com os direitos de cidadania, mas tem em si a 
contradição - pode ser assistencialista ou pode gerar mais consciência das pessoas atendidas nas suas lutas no sentido de transformação social; é contraditória [...] pode atender ao mesmo tempo tanto as demandas do capital quanto as do trabalho, dependendo da correlação de forças".

Nestes termos, uma política social parte de um processo histórico e político no qual a sociedade irá definir o que considera como necessidade e que deverá ter aporte público (HÖFLING, 2001; KORNIS, 1994; PEREIRA, 1996; RAICHELIS, 1998). A abrangência das provisões em qualidade, quantidade, cobertura e garantias, modos de gestão e financiamento define o regime da política social em cada realidade nacional.

Desse modo, torna-se necessária a integração de diferentes áreas de conhecimento para o desvendamento de problemas de natureza pública e política. $O$ estudo das políticas sociais e da administração pública depende da identificação de problemáticas advindas de cada realidade para a elaboração de leis prevendo comportamentos sociais e a antecipação de políticas efetivas.

Importante ressaltar, baseado em Rua (2009), que a política pública se diferencia da decisão política. Segundo a autora, a política pública abrange ações e estratégias para implementar as decisões e a decisão política em meio a uma gama de alternativas associadas às preferências dos atores envolvidos - nem toda decisão política torna-se uma política pública, mas toda política pública requer uma decisão política.

Na década de 90, os autores Howlett e Ramesh propuseram uma trajetória de política pública por meio de cinco estágios, quais sejam: construção da agenda (agenda-setting), formulação da política (design), tomada de decisão (escolha), implementação e avaliação. No modelo proposto, enfatiza-se a concepção de que uma política tem como ponto de partida a percepção de problemas, posteriormente é conduzida para a formulação de propostas e tomada de decisão, sucedem implementação e avaliação; reinicia-se, então, um novo momento na visualização de problemas e formulação de política.

Desta perspectiva, a construção e a prática de decisões políticas (policy) são traduzidas utilizando-se o modelo de elaboração das políticas públicas por etapas, conhecida por policy cycle, em que diversos atores governamentais (políticos, juízes, burocracia) ou não governamentais (grupos de interesse, partidos políticos, meios de comunicação, destinatários das políticas públicas, organizações não governamentais) exercem sua influência.

As fragilidades do modelo, principalmente por se dar em etapas e ser procedimental, são transpostas na medida em que se pensa sob o olhar do ciclo em espiral e se considera a complexidade da realidade social.

Para Resende (2014, p. 13-14), a

“[...] análise da política pública por etapas ou estágios criou diferentes linhas de pesquisa que focam em determinada fase - que seguem questões, perspectivas analíticas e métodos específicos - em vez de analisar todo o ciclo (Jann e Wegrich, 2007). Além disso, o processo político não segue esta sequência em etapas distintas. Na verdade, estas etapas estão constantemente ligadas e envolvidas em um processo contínuo".

Arremate-se o raciocínio tendo em conta que:

“[...] na metodologia de análise das políticas sociais e programas é preciso fazer a decomposição para entender as políticas: a análise dos discursos e a análise das ações (dos programas que materializam a política). Não se pode analisar só os resultados e impactos, pois algumas ações resultam inoperantes, por inadequadas e insuficientes, pelo comportamento dos afetados, pelas circunstâncias do momento que não eram previstas; portanto é preciso analisar todo o processo. A análise é complexa, porque é preciso descobrir a correlação de forças, os elementos que pesam na decisão, a ideologia por trás dos discursos, a teoria da mudança que orientou a política pública. (TANEZINI, 2004, p. 37)”.

\section{CONTEXTUALIZAÇÃO TEMÁTICA}

O Estado de bem-estar de base keynesiana e social-democrata é uma instituição do século XX, caracterizada por uma relação entre Estado e sociedade antes inexistente e regida por princípios que, em compasso com as reivindicações sociais do 
período, privilegiam determinados objetivos e políticas (policies): extensão dos direitos sociais, oferta universal de serviços sociais, preocupação com pleno emprego e institucionalização da assistência social como rede de defesa contra a pobreza absoluta e meio de garantir a manutenção de padrões mínimos de atenção às necessidades humanas básicas (NETTO, 1993; COUTINHO, 2005)

Este enfoque sobre a cidadania reuniu os direitos de igualdade política, garantindo a todos os naturais do território o direito de acesso ao conjunto de benefícios sociais que constituíram o Welfare State.

Na perspectiva liberal, compreende-se a cidadania como resultante de um progressivo afastamento do Estado do cotidiano dos cidadãos, permitindo que cada um cuide de seus interesses à sua maneira, competindo com os demais munido dos recursos de que dispuser, nos campos político e econômico. Assim, o mercado é soberano, prevalecem os interesses individuais sobre os coletivos.

Dessa forma, rompe-se a sociedade em indivíduos consumidores e se dissolve qualquer forma de comunidade e de pertencimento social para além do mercado.

Em oposição se encontra a perspectiva democrática, por meio da qual se constata que o ponto de partida para tal concepção é demasiado desigual para ser aceito, ele deve ser corrigido por uma distribuição de renda que permita uma genuína igualdade de oportunidades entre todos os indivíduos. Essa lógica se baseia na universalização dos direitos sociais (PEREIRA, 2008).

Ao longo da história, pode-se averiguar que, no Brasil, a conquista pelos direitos sociais universais é decorrente das lutas democráticas e populares, e não advindas da elite política ou do Estado. No país são emblemáticas: a concentração de renda, a propriedade territorial e o poder, a precariedade do trabalho, as políticas precárias de preservação ambiental e, nos últimos anos, o desenvolvimento da política de assistência social focado em programas de transferência de renda - restringe-se ao aumento de consumo das classes mais pauperizadas da sociedade, o que não se traduz em melhoria na qualidade de vida.

Assim, "[...] o modelo de desenvolvimento socialmente justo se baseia na universalização dos direitos sociais e não apenas na ideia de ampliação do consumo, que é objetivo do mercado. As disputas entre os interesses públicos e do mercado dependerão da correlação destas forças políticas" (CENTRO BRASILEIRO DE ESTUDOS DA SAÚDE, 2011, p. 2).

Em linhas gerais, acredita-se que a democracia brasileira necessita ser reorientada, tendo em consideração a perspectiva social-desenvolvimentista, a fim de possibilitar, de fato, um presente e um futuro para a sua população em padrões aceitáveis de desenvolvimento social e econômico, mantendo um elevado grau de realização humana e cultural, bem como a proteção e o uso racional dos seus recursos naturais (NOBRE, 2013).

Desse modo, concorda-se com LOBATO (2009, p. 199):

“Há que se tomar a proteção social ampliada e constante dos cidadãos como referência. A seguridade deve ser mais do que o guarda-chuva que garante recursos vinculados a sistemas estruturados de serviços e benefícios, para ser a referência do pensar e atuar a proteção social de hoje e do futuro [...]. Há que associar as políticas focalizadas com as políticas universais e integrá-las em sistemas universais de seguridade e proteção social. [...]

A Constituição de 88 trouxe, mais do que tudo, e com todas as suas limitações, o ideal da democracia com justiça social. É possível e necessário reconstruir esse ideal”.

Hoje, no Brasil, há um debate em torno da situação das classes sociais. Trata-se de uma "nova classe trabalhadora" (CHAUI, 2013; SOUZA, 2012) ou uma "nova classe média" (POCHMANN, 2010; NERI, 2012)?

É inegável que essa discussão é complexa. Mas é fato que a estrutura de classe social na sociedade capitalista deve ser compreendida de acordo com a maneira pela qual ela se insere na relação entre os meios sociais privados de produção, as forças produtivas e as relações de produção.

Desse modo, não significa a emergência de uma classe o que se identifica como uma nova classe média brasileira baseada em indicadores que consideram profissão, gostos de consumo, renda familiar e escolaridade - critérios extrínsecos das pesquisas de mercado (classes A, B, C, D e E). 
Chaui (2013), analisando nossa realidade, pontua que a nova classe trabalhadora é o resultado das políticas econômicas contrárias ao neoliberalismo. Ela nasce no interior da formulação neoliberal: da fragmentação da produção industrial, da privatização e terceirização dessa produção, do poderio do capital financeiro e da mudança na relação entre conhecimento e produção.

Neri (2013) argumenta que "[...] os sociólogos podem relaxar, pois não estamos falando de classes sociais (operariado, burguesia, capitalistas etc.), mas de estratos econômicos. Leia-se dinheiro no bolso, segundo os economistas a parte mais sensível da anatomia humana".

Polêmica à parte, constata-se que o aumento do consumo não representa necessariamente o alcance de um nível satisfatório de qualidade de vida. Isso implica a necessidade de conhecer as famílias, seus estilos e saber como atender suas necessidades de saúde.

Para Ulisses de Carvalho (2008, p. 100),

O estar com câncer pode trazer uma série de implicações em níveis: físico, emocional, afetivo, profissional e financeiro para o sujeito enfermo [...] se o processo de adoecimento tem uma série de determinantes sociais relacionados às condições de vida, o enfrentamento a doença tem relação direta com os contextos socioeconômico e cultural em que vivem os pacientes e seus familiares. Estamos diante de desigualdades sociais que não são naturais, iniquidades que produzem impacto na condição de saúde das pessoas e que vão dificultar o lidar com uma doença grave como o câncer.

É importante ressaltar que os profissionais de saúde atuam respeitando a autonomia do paciente, que é compreendida como um direito. Busca-se a identificação dos temas centrais que circulam em torno da família, como, por exemplo, o desejo do paciente em aprofundar os conhecimentos sobre a doença, o momento que está vivendo e sua dinâmica de compartilhamento com os membros de sua unidade familiar; rastreiam-se as condições dos cuidados disponíveis no lar e, se for o caso, incentiva-se e viabiliza-se o atendimento domiciliar; disponibilizam-se informações acerca do preparo para o plano de cuidado avançado com a equipe de saúde.

A chave do segredo para um trabalho que atua simultaneamente com uma gama de profissionais de diferentes áreas da saúde ou afins, como é o caso da área de Cuidados Paliativos, está em um sistema de integração que permita não apenas uma comunicação adequada, mas também o monitoramento dos objetivos e estratégias adotados como prioridade.

Entre as equipes de paliativistas é comum a reflexão sobre os cuidados. Surgem questões como: tudo que foi proposto para os cuidados do paciente foi realizado a contento? Onde ocorreu o acerto ou o erro? Deixou-se de ofertar algum suporte?

Considera-se que o caminho mais seguro é o traçado geral do plano de cuidados do paciente antes de seu processo de admissão para tratamento paliativo. Aqui, o processo de comunicação deve ser transparente, objetivo, envolvente e pactuado entre as partes interessadas.

Assim, defende-se um modelo de plano de cuidado que dê conta dos desejos do paciente - considerando que ao longo do tempo (mês/ano) ele será influenciado por mudanças no diagnóstico/prognóstico, internação, habilidade, humor, estado de saúde, circunstâncias social e funcional (por isso a importância de ser validado a cada seis meses) - e do processo de trabalho futuro, ou seja, um grande traçado sobre os aspectos clínico, social, psicológico e espiritual que serão necessários em cada caso.

É imperioso atentar para o fato de que os comitês de bioética são um espaço apropriado de discussão e resolução dos dilemas como testamento vital etc. Evidencia-se que a implantação de um modelo de plano de cuidado serve para facilitar a ação e não para ser mais um papel a ser preenchido. Por exemplo: se um assistente social se depara com uma família em estado de extrema pobreza e um dos seus membros tem uma estimativa de vida de seis meses, é oportuno propor intervenções em nível de recursos assistenciais, associar tempo/necessidade e elevar, consequentemente, a resolutividade nas ações.

Neste sentido, recorre-se a Ulisses de Carvalho (2008, p. 101):

“É necessário reconhecer a realidade de vida do paciente e de sua família: a organização familiar, a qualidade das relações, os limites de compreensão da situação, o papel do enfermo na família, o impacto às atividades laborativas dos potenciais cuidadores, as condições habitacionais, a renda familiar. Enfim, compreender a complexidade que é ter um enfermo grave para cuidar, especialmente quando as condições de vida e trabalho são precárias". 
Para Dadalto (2010), é fundamental que o indivíduo tenha o direito de elaborar uma declaração prévia de vontade ou testamento vital, assim como o de participar de forma sistemática e consciente de seu tratamento paliativo. Apesar de não existir no Brasil uma legislação específica sobre o tema, é válido o paciente registrar seu testamento vital na ficha médica ou no prontuário, de acordo com o Conselho Federal de Medicina, por meio da resolução n. 1995/12, aprovada em 30 de agosto de 2012.

Hoje, já estão disponíveis via internet o maior banco de dados sobre o testamento vital - trata-se do Registro Nacional de Testamento Vital (RENTEV) - e um portal sobre o assunto elaborado pela autora acima referida. São dispositivos imprescindíveis para o entendimento da natureza dos Cuidados Paliativos e de como usufruir deles de forma autônoma e consciente.

Em relação à comunicação em saúde, é primordial que os profissionais estejam preparados para o enfrentamento do impacto da má notícia quanto à viabilização do desejo do futuro paciente em relação aos cuidados que espera em seus últimos dias de vida FROSSARD (2014). É necessária, na comunicação de notícias difíceis, a associação entre a técnica e a emoção na prestação de atenção à assistência paliativa. Daí a importância de programas de educação permanente nas instituições visando ao aprimoramento de seus profissionais.

\section{O MODELO DE ATENÇÃo À SAÚDE: OS CUIDADOS PALIATIVOS}

Os Cuidados Paliativos constituem-se uma área de conhecimento cujo modelo de intervenção é baseado na reumanização do processo de cuidar. $\mathrm{O}$ ato de cuidar é compreendido como resultado de uma combinação de responsabilidade e ética. Baseia-se no respeito à existência como um direito.

Uma de suas principais características é a desospitalização dos cuidados por meio da prestação da assistência em domicílio (ver quadro 1: as principais características do modelo de atenção à saúde em Cuidados Paliativos) - lócus privilegiado para a identificação das chamadas refrações da questão social, como por exemplo: moradias precárias, violência, fome, desemprego e abandono, etc.

Recorde-se que é na modalidade de assistência domiciliar que as ações intersetoriais são cruciais para uma boa prática em saúde, pois é vital a articulação e utilização dos recursos existentes na rede (Atenção Básica de Saúde; Centro de Referência de Assistência Social - CRAS; Centro de Referência Especializado de Assistência Social - CREAS; Unidade de Pronto Atendimento - UPA; entre outros).

A partir de 2000, os Cuidados Paliativos apresentaram um crescimento de serviços significativo mais desigual (ANCP, 2013). Há concentração dos serviços na região Sudeste e, em especial, em São Paulo, o que demonstra grandes diferenças de ofertas entre as regiões brasileiras. Importa elucidar que o país carece de uma legislação sobre Cuidados Paliativos como os existentes em vários países, conforme dados publicados no Atlas de Cuidados Paliativos en Latinoamerica, (ASSOCIACIÓN LATINOAMERICANA DE CUIDADOS PALIATIVOS, 2013). Desse modo, há um caminho importante a percorrer para a universalização da assistência neste âmbito e a sua consolidação como política pública.

Ressalte-se que no país não há, no momento, parâmetros oficiais para precisar as necessidades dessa área de atuação em saúde. Considerando expressivos os dados disponibilizados pelo DATASUS (2006) sobre óbitos no Brasil decorrentes de doenças de evolução crônica ou degenerativas e neoplasias - 914 mil pessoas morreram hospitalizadas ou em seus lares (ANCP, 2012) - e a recomendação da OMS para que todos os pacientes recebam a abordagem dos Cuidados Paliativos, o indicativo é a utilização no país do critério do prognóstico de tempo de vida designado em seis meses de expectativa de vida (ARANTES, ANCP, 2012).

Desde o mês de novembro de 2014, o Instituto Nacional de Câncer, disponibilizou uma ferramenta digital intitulada Atlas de Mortalidade por Câncer, que tem como base o Sistema de Informações sobre Mortalidade (SIM) do Ministério da Saúde e permite aos profissionais de saúde, por exemplo, visualizar o andamento da mortalidade por câncer e a análise da relação entre os óbitos e as variáveis associadas a estilo de vida, condições ambientais e diferenças populacionais. Esta ferramenta colabora também na determinação de prioridades à prevenção e ao controle de câncer e no fomento à pesquisa.

Desse modo, a iniciativa registrada acima é um passo importante 
[...]" para que se possa discutir custo, avaliação e planejamento de sistemas e serviços - na perspectiva da política de saúde - no que se refere ao processo de morrer, é necessária pesquisa para subsidiar decisões [...] é preciso produzir informações, o que representa uma demanda para a área de vigilância, no que diz respeito tanto à construção de indicadores quanto à coleta sistemática de dados. Só assim o problema relacionado com o processo de morrer deixará de ser invisível”. (BATISTA et al., 2010, p. 294)

A seguir, apresentam-se as principais características do modelo de atenção à saúde em Cuidados Paliativos no Quadro 1.

\section{Quadro 1}

Características de modelo de atenção à saúde em Cuidados Paliativos

\begin{tabular}{|c|c|c|}
\hline & $\begin{array}{c}\text { MODELO DE ATENÇÃO À SAÚDE } \\
\text { TRADICIONAL }\end{array}$ & $\begin{array}{c}\text { MODELO DE ATENÇÃO À SAÚDE CUIDADOS } \\
\text { PALIATIVOS }\end{array}$ \\
\hline Concepção de cuidados & $\begin{array}{l}\text { Modelo biomédico - curativo e } \\
\text { hospitalocêntrico }\end{array}$ & $\begin{array}{l}\text { Modelo focado na desospitalização dos } \\
\text { cuidados, na prevenção e alívio do sofrimento } \\
\text { humano }\end{array}$ \\
\hline Objetivos & $\begin{array}{l}\text { Tratar, medicar e curar - O indivíduo } \\
\text { Foco em especialidades } \\
\text { Concepção de saúde como ausência de } \\
\text { doença }\end{array}$ & $\begin{array}{l}\text { Controle de dor e de sintomas } \\
\text { Promoção de qualidade de vida } \\
\text { Foco na integração de diferentes áreas de } \\
\text { conhecimento em saúde } \\
\text { Ênfase no cuidado com o paciente e a família } \\
\text { Concepção ampliada de saúde com a introdução } \\
\text { do conceito de espiritualidade }\end{array}$ \\
\hline Organização do trabalho & $\begin{array}{l}\text { Ênfase no trabalho na abordagem } \\
\text { unidisciplinar } \\
\text { Trabalho desenvolvido de forma } \\
\text { fragmentada } \\
\text { Foco no ambiente hospitalar }\end{array}$ & $\begin{array}{l}\text { Ênfase no trabalho na abordagem interdisciplinar } \\
\text { Sistema de atenção à saúde integrado: do } \\
\text { diagnóstico à finitude } \\
\text { Foco na assistência domiciliar; hospital-dia, } \\
\text { integração com as estratégias de Saúde da } \\
\text { Família, ambulatório presencial e à distância, } \\
\text { hospedarias } \\
\text { Cuidados planejados: planejar, orientar e avaliar } \\
\text { ações integradas com a definição de objetivos, } \\
\text { metas e indicadores de qualidade. }\end{array}$ \\
\hline
\end{tabular}

Fonte: elaboração própria com base em dados disponibilizados pela ANCP (2012).

Todas as organizações que prestam cuidados paliativos necessitam gerir sua estrutura organizacional para atingir os objetivos a que se propõem. No caso do setor público, espera-se que suas ações sejam desenvolvidas de maneira eficiente, eficaz, ágil, participativa e transparente, e que seus resultados sejam capazes de interferir na realidade e transformá-la. Para atingir o resultado projetado - transformar a realidade brasileira em relação à qualidade do processo de finitude humana -, espera-se uma adequada gestão de cuidados.

Verificou-se que o desenvolvimento do modelo de Cuidados Paliativos no Brasil é recente e não imune aos problemas de natureza técnica e ética. Para fazer a diferença nesta esfera de atenção, são prementes a eliminação de preconceitos em relação à finitude humana e à introdução de mecanismos para a promoção de um adequado cuidado coadunado com a realidade. Isto implica, antes de tudo, que os planos nacionais e regionais estabeleçam metas factíveis e priorizem ações originais cujos objetivos são a qualidade do serviço e os interesses de pacientes, seus familiares e afins. Portanto, sem gestão integrada não há mudanças efetivas. 
O Brasil ocupa a 38a posição no ranking de qualidade de morte entre 40 países, conforme divulgado em 2012 pela Economist Intelligence Unit, empresa de consultoria integrante do grupo da revista The Economist, que classificou 40 países em um ranking de qualidade de morte. Este estudo considera alguns fatores que indicam a qualidade da morte, tais como: os cuidados prestados aos pacientes no fim da vida e a quantidade de analgésicos disponíveis para o controle da dor.

Nessa direção, Rodrigues (2012), de forma oportuna, registra a necessária alteração da legislação brasileira no que se refere à dispensação de analgésicos, em especial os opióides. Para ele, "[...] na atenção básica, a tarefa de prescrever e dispensar os opióides ainda permanece uma situação de difícil desfecho" (ANCP, 2012, p. 92).

Recorde-se que o conceito de dor é complexo e abarca fatores físicos, sociais e espirituais. É uma experiência de cunho individual e, portanto, carregada de subjetividade. Daí a importância da equipe interprofissional para um adequado manejo de controle de sintomas e de dor.

Para a reversão do quadro explicitado anteriormente, são necessários o enfrentamento de obstáculos nas áreas de recursos humanos, a disseminação de informação (há muito desconhecimento e tabu sobre a área em questão), a logística de medicamentos e a distribuição de serviços por região atendendo às especificidades locais.

É pertinente registrar que a Academia Nacional de Cuidados Paliativos (ANCP), fundada em 2005, tem sido responsável pelos principais avanços na área em foco, como por exemplo: estabelecimento de critérios de qualidade para os serviços de Cuidados Paliativos, empenho incessante para a regularização profissional do paliativista, busca de interlocução com os ministérios da Saúde, da Educação, o Conselho Federal de Medicina (CFM) e a Associação Médica Brasileira (AMB). Além disso, contribuiu de forma expressiva para a inclusão dos Cuidados Paliativos como princípio fundamental no novo Código de Ética Médica.

Registre-se que o Estado de São Paulo inova ao propor uma rede de Cuidados Paliativos na Saúde Pública do Estado, a ser implantada até 2017 por meio do projeto de Lei no 599, de 2014, em tramitação. Esta lei prevê que todos os municípios com mais de cem mil habitantes terão uma rede de Cuidados Paliativos com cobertura total à população local, e os municípios com menos de cem mil habitantes contarão com centro de referência em Cuidados Paliativos. Trata-se de uma iniciativa que deveria ser efetivada em todo o território nacional.

Considerando que as etapas do ciclo de políticas públicas são compreendidas de forma não linear e sequencial, pois dependem da correlação de forças presentes no real, identificam-se os principais problemas da área em foco. Essas etapas são resumidas por: formulação (a concepção da política pelos tomadores de decisão), implementação (efetivação da política em ação) e avaliação (a comparação entre os resultados planejados e os efetivamente alcançados). Observe-se o Quadro 2 a seguir.

\section{Quadro 2 Ciclo de política}

\begin{tabular}{|c|c|c|}
\hline \multicolumn{2}{|c|}{ FASE } & ETAPA \\
\hline \multirow{4}{*}{ FORMULAÇÃO } & $\begin{array}{l}\text { Identificação do } \\
\text { Problema }\end{array}$ & $\begin{array}{c}\text { Expansão e consolidação dos Cuidados Paliativos } \\
\text { no Brasil }\end{array}$ \\
\hline & Inclusão na Agenda & $\begin{array}{c}\text { Legislação que regule os Cuidados Paliativos em } \\
\text { nível nacional }\end{array}$ \\
\hline & Formulação da Política & $\begin{array}{c}\text { Estimular a criação de redes de Cuidados } \\
\text { Paliativos na Saúde Pública }\end{array}$ \\
\hline & Tomada de Decisão & Encaminhar proposta para o Poder Legislativo \\
\hline IMPLEMENTAÇÃO & Implementação & $\begin{array}{c}\text { Regulamentação e operacionalização da rede em } \\
\text { três anos }\end{array}$ \\
\hline
\end{tabular}

Fonte: elaboração própria com base em dados disponibilizados pela ANCP (2012). 
Diante de todos os pontos apresentados e tendo como referência o modelo teórico do ciclo de políticas públicas de Howlett e Ramesh (1995), evidencia-se que, na montagem da agenda, a primeira iniciativa está no reconhecimento do problema como de relevância pública. No caso analisado, entende-se que com uma experiência inovadora e relevante, em nível regional, é possível replicá-la em todo o território nacional, respeitando as especificidades locais.

Desse modo, reconhecido o problema, é necessária a sua inserção na agenda do governo em um movimento envolvendo diferentes atores: Conselho Federal de Medicina, Academia Nacional de Cuidados Paliativos, deputados da chamada bancada da saúde, empresários, instituições de saúde, usuários dos serviços, etc.

Sabe-se que hoje o Congresso Nacional está mais sensível às necessidades da área de saúde, em razão de uma preocupação em atender o clamor popular (desde os movimentos de rua de 2013, ficou claramente evidenciada a insatisfação do povo brasileiro com a oferta de serviços públicos de saúde). E, mesmo com um cenário nacional de desaceleração econômica e de ajuste fiscal, os governantes vêm reafirmando que preservarão os investimentos na área de saúde. Infelizmente não foi o que ocorreu. Contudo, considerando os estudos realizados e/ou divulgados pela Academia Nacional de Cuidados Paliativos, é certa a constatação de que os Cuidados Paliativos diminuem os custos dos serviços de saúde, além de beneficiarem os pacientes e seus familiares.

Assim, parece haver um cenário favorável, em médio prazo, ao processo de implementação da Rede Nacional de Cuidados Paliativos.

\section{ACESSIBILIDADE E CUIDADOS PALIATIVOS}

Considera-se que a disponibilidade adequada para os usuários dos serviços socioassistenciais e sociojurídicos está no ponto de intersecção entre saúde e segurança. Nesse caso, cabe recordar as considerações de Sposati $(2009$, p. 182):

"A assistência social, por sua vez, opera no âmbito dos serviços e dos benefícios. No caso dos serviços, sua relação direta é reduzida pela mediação das entidades sociais. No caso dos benefícios, é preciso distinguir os benefícios continuados e de transferência de renda de âmbito federal, que utilizam a rede bancária para transferir o valor financeiro ao usuário, e os benefícios eventuais de âmbito local, que utilizam da relação face a face entre o técnico municipal e o usuário".

Assim, segundo a NOB-SUAS (MINISTÉRIO DO DESENVOLVIMENTO SOCIAL E COMBATE A FOME, 2010):

"A função da vigilância socioassistencial consiste em desenvolver capacidades e meios técnicos para que os gestores e profissionais da Assistência Social possam conhecer a presença das formas de vulnerabilidade social da população e do território pelo qual são responsáveis, induzindo o planejamento de ações preventivas e contribuindo para o aprimoramento das ações que visem à restauração de direitos violados e à interrupção de situações de violência".

Entende-se por segurança social a proteção aos cidadãos em vulnerabilidade e, em especial, aos vulnerados. 0 artigo 203 da Constituição Federal vigente no país afirma que a "[...] assistência social será prestada a quem dela necessitar, independentemente de contribuição à seguridade social". Ficam evidenciados tratamentos distintos entre a assistência social e a previdência social. A primeira não está condicionada a contraprestação por parte dos beneficiários e a segunda está condicionada às suas contribuições (seguro).

Assim, considerando a família como um núcleo integrante das práticas que moldam a esfera de reprodução social, cabe iluminar o que se compreende pelos termos: "vulnerabilidade", "vulneração" e "risco social", considerando que o Estado deve assegurar proteção aos seus cidadãos em todos os ciclos de vida - aqui, pensa-se na eliminação do estabelecimento de mínimos sociais, bem como no de cobertura por segmentos sociais relacionados a níveis de proteção social.

No exame da atual política social de assistência social em curso no país, é possível a identificação do termo "vulnerabilidade". A Constituição Federal de 1988, no Capítulo II, artigo 6으, destaca os direitos sociais, que incluem a saúde, a educação, o trabalho, o lazer e a previdência, cujos objetivos são garantir a proteção à maternidade, à infância, à velhice, entre outros. 
Para fins desse estudo, destaca-se a Lei no 12.435, de 6 de julho de 2011, que altera a Lei no 8.742, de 7 de dezembro de 1993, a qual dispõe sobre a organização da Assistência Social no seu art. 2ㅇ, no qual seus objetivos são abordados. Nota-se o uso de termos genéricos como "contingência social" e "vulnerabilidade" na perspectiva da vigilância socioassistencial com base na noção de territórios e ações de proteção às famílias.

Realizando uma interlocução teórica com diversos autores, Janczura (2012) aponta a necessidade de se fazer uma distinção entre risco e vulnerabilidade - apesar de ambos terem uma relação estreita. Para a autora, a noção de risco se refere à situação de grupos (conceito muito usado pelos epidemiologistas), o que pressupõe uma exposição mais significativa às adversidades.

De acordo com a literatura especializada (KOTTOW, 2001; JANCZURA, 2012; SCHRAMM, 2005), o termo "vulnerabilidade" sugere algo que pode acontecer ou não, ou seja, uma contingência. Schramm e Kottow (2001) esclarecem que para ser vulnerável basta estar vivo; sendo assim, nem todas as pessoas são vulneradas de fato.

Desse modo, faz-se necessária a identificação de fatores que tornam uma pessoa ou grupo vulnerado, ou seja, em condição de vulnerabilidade intensificada, carecendo, assim, de medidas protetoras especiais, como é o caso de muitos pacientes e de suas famílias inseridos em programas de Cuidados Paliativos (abandono com perda total de laços sociais, insegurança quanto ao futuro, inacessibilidade a serviços, falecimento de indigentes, invisibilidade social e muito longe de uma vida e de uma finitude dignas).

Segundo o Censo Demográfico do IBGE (2010), características da população e dos domicílios, na média brasileira as mulheres são chefes do domicílio em $38,7 \%$ das residências. No Rio de Janeiro, as mulheres representam $46,5 \%$ dos 2,14 milhões de chefes de família, enquanto $21,1 \%$ delas declararam não ter renda ou ganhar até um salário mínimo.

De acordo com o Instituto Nacional do Câncer, em 2010 os cânceres de mama e de útero, por exemplo, foram as causas de morte de 16,6 mil pessoas. De acordo com dados disponibilizados pelo Informe Inca (2015), o estudo Concord-2, da revista inglesa The Lancet (realizado em 2014), confirma que o Brasil teve um aumento de 87\%, em 2005, na sobrevida de pacientes diagnosticados com câncer de mama em comparação ao ano de 2000, com 78\%, em estudo que envolveu 67 países. Tal resultado é decorrente da expansão do acesso da população aos serviços de saúde, como exames de deteç̧ão e tratamentos. Atualmente, está em vigor a lei 12.732/12, que assegura aos pacientes com câncer o início do tratamento no Sistema Único de Saúde (SUS) em no máximo 60 dias após a inclusão da doença em seu prontuário.

Recorde-se que a acessibilidade, para Travassos e Martins (2004, p. 191), refere-se "[...] às características dos serviços e dos recursos de saúde que facilitam ou limitam seu uso por potenciais usuários. A acessibilidade corresponde a características dos serviços que assumem significado quando analisadas à luz do impacto que exercem na capacidade da população de usá-los".

Neste sentido, destaca-se o Sistema Nacional de Regulação (SISREG) para a democratização e transparência no acesso aos serviços (apesar das dificuldades em sua implantação). Trata-se de um software de gerenciamento de todo o complexo regulatório ofertado pelo Ministério da Saúde, que vai da rede básica à internação hospitalar, visando à humanização dos serviços, ao maior controle do fluxo e à otimização na utilização dos recursos, além da integração da regulação com as áreas de avaliação, controle e auditoria (BRASIL, 2013).

\section{HUMANIZAÇÃO E CUIDADOS PALIATIVOS}

OLIVEIRA (2007) entende o tema da humanização da assistência em saúde como um processo de transformação da cultura institucional que reconhece e valoriza os aspectos subjetivos, históricos e socioculturais de usuários e profissionais, assim como funcionamentos institucionais importantes para a compreensão dos problemas e elaboração de ações que promovam boas condições de trabalho e qualidade de atendimento.

O tema da humanização na saúde alçou um novo status, segundo Deslandes (2004), com a regulamentação do Programa Nacional de Humanização da Assistência Hospitalar (PNHAH) em 2000. O Ministério da Saúde, em 2004, expande esse projeto para todos os níveis de atenção ao implantar a Política Nacional de Humanização (PNH) do SUS. Seu marco teórico-político configura-se em torno da humanização das práticas de atenção e gestão em todas as esferas do SUS, entendida como uma dimensão fundamental do sistema de saúde, a operar transversalmente em toda a rede do SUS. 
Desse modo, a humanização na saúde deixa de ser fragmentada em programas e passa a ser uma política transversal que perpassa as diferentes ações e instâncias gestoras do SUS. É importante destacar a característica polissêmica do tema humanização. Deslandes (2004), ao analisar o documento oficial do PNHAH, busca definir os sentidos atribuídos à humanização impressos no discurso do programa.

Dessa perspectiva, humanizar é garantir à palavra a sua dignidade ética (DESLANDES, 2004, p. 11). A PNH é norteada por aspectos como a valorização da dimensão subjetiva, coletiva e social em todas as práticas de atenção e gestão no SUS, fortalecendo o compromisso com os direitos dos cidadãos, o trabalho em equipe multiprofissional, a construção de redes cooperativas, autonomia, protagonismos dos sujeitos coletivos e sua corresponsabilidade nos processos de gestão e atenção. Ressalte-se, ainda, que esta política visa ao fortalecimento do controle social em todas as instâncias do SUS, ao compromisso com a democratização das relações de trabalho e valorização dos trabalhadores e da ambiência, com organização de espaços saudáveis e acolhedores de trabalho.

Como estratégias da PNH no nível da Atenção Básica, por exemplo, tem-se: o acolhimento (que compreende a entrada do usuário no sistema de saúde, a responsabilização integral de suas necessidades, o vínculo e a atenção resolutiva aos seus problemas) e a abordagem orientada por projetos terapêuticos de saúde individual e coletiva (na perspectiva do exercício de uma clínica ampliada, capaz de aumentar a autonomia dos sujeitos, e do estabelecimento de redes de saúde, incluindo todos os atores e equipamentos sociais).

Considerando a relevância das transformações desencadeadas pelas recentes políticas de humanização e de Atenção Básica no SUS, é importante assinalar que as estratégias da PNH coincidem com os próprios princípios do SUS, especialmente no que se refere à universalidade do acesso e do direito à saúde, à integralidade e à equidade nas ações como necessidades fundamentais ao exercício da cidadania. Tais princípios constituem o arcabouço político-organizativo do sistema, guiado imperativamente por quesitos éticos. Dessa maneira, torna-se necessário o reconhecimento da repercussão da PNH nos âmbitos político-organizativo e técnico-operativo, no sentido de identificar as implicações éticas à garantia do direito à atenção integral à saúde.

Entende-se que a política social deve atuar na perspectiva de integração. A de assistência social, no caso, deve promover leis, em todos os níveis de governo, que assegurem o direito à assistência social às pessoas em condições de vulneração, enfatizando-se o trabalho centrado na família. Aqui, o campo dos Cuidados Paliativos merece um destaque.

Para Demo (2006, p. 7), pobreza não deve ser definida tão somente como carência material: “[...] pobreza não é miséria pura e simples, mas aquela impingida, discriminatória, ou mais que tudo, aquela da maioria em função do enriquecimento da minoria. Pobre é, sobretudo, quem faz a riqueza do outro, sem dela participar. Pobreza, em sua essência, é discriminação, injustiça".

Compreender os Cuidados Paliativos na perspectiva da garantia de direitos em consonância com a Política de Humanização da Atenção e da Gestão (PNH) é pensar além do controle de dor e de sintomas, da criança ao idoso, estendendo os cuidados na perspectiva da prevenção de situações-limite como, por exemplo: pacientes abandonados pela família, famílias em disputas por patrimônio e herança, disputas por pensão por morte (casos de pacientes com mais de uma família), dificuldades para o acesso a uma vaga hospitalar, pacientes que falecem e deixam menores sem definição de guarda, pacientes oriundos das ruas que morrem como indigentes e cujo funeral de forma mais ágil é dificultado em virtude da burocracia das instituições de saúde, pacientes que não têm como manter uma alimentação adequada, pacientes moradores de áreas de risco e com moradia precária etc.

É notória, no país, a expressiva contribuição do sistema sociojurídico no âmbito da saúde e, em especial, na efetivação dos direitos dos pacientes. Muitos conflitos envolvendo bens materiais de casais homoafetivos com suas famílias, por exemplo, foram solucionados com o reconhecimento da união entre pessoas do mesmo sexo. Sem dúvida, a área de Direito de Família - muito requisitada nos Cuidados Paliativos - humanizou-se atendendo os novos rearranjos familiares. A legislação foi transformada visando ao acompanhamento da dinâmica da realidade - como a guarda compartilhada, o casamento entre pessoas do mesmo sexo, o divórcio incondicional, entre outros.

Observe-se, a seguir, o Figura 1: 
Figura 1

Os cuidados paliativos e a acessibilidade

\begin{tabular}{|c|c|c|}
\hline ENTRADA & ENTRADA & ENTRADA \\
\hline $\begin{array}{l}\text { Rede de Atenção } \\
\text { Básica } \\
\text { Promoção } \\
\text { Prevenção } \\
\text { Diagnóstico Precoce } \\
\text { Acompanhamento } \\
\quad \text { Reabilitação } \\
\text { Medicamentos } \\
\text { Estética } \\
\text { Nutrição } \\
\text { Cuidados Paliativos }\end{array}$ & $\begin{array}{l}\text { Rede de Atenção de } \\
\text { Média Complexidade } \\
\text { Especialidades } \\
\text { Tratamento } \\
\text { Diagnóstico Precoce } \\
\text { e Oportuno } \\
\text { Acompanhamento } \\
\text { Reabiltação } \\
\text { Medicamentos } \\
\text { Estética } \\
\text { Nutrição } \\
\text { Cuidados Paliativos }\end{array}$ & $\begin{array}{l}\text { Rede de Atenção de } \\
\text { Alta Complexidade } \\
\text { Diagnostico } \\
\text { Prognostico } \\
\text { Tratamento } \\
\text { Acompanhamento } \\
\text { Reabilicaçäo } \\
\text { Medicamentos } \\
\text { Estética } \\
\text { Nutrição } \\
\text { Cuidados Paliativos } \\
\text { Suporte } \\
\text { Acesso (transpone) } \\
\text { Medicamemtos } \\
\text { Nutrição }\end{array}$ \\
\hline & E MERG Ê NCIA & \\
\hline SAÍDA & SAÍDA & SAÍDA \\
\hline $\begin{array}{l}\text { Sistema sociojuridico Just } \\
\text { Universidades (escritórios } \\
\text { Sistemas socioassistenciai }\end{array}$ & $\begin{array}{l}\text { ARANTINDO DIREITOS } \\
\text { tadual e Federal, Ministérios Públi } \\
\text { os) } \\
\text { S/ CREAS, casas de acolhimento, }\end{array}$ & $\begin{array}{l}\text { Cos, Defensorias Públicas } \\
\text { ONCS) }\end{array}$ \\
\hline
\end{tabular}

Fonte: elaboração própria com base nos dados disponibilizados pela ANCP (2012).

Na política de Assistência Social, existem três níveis de complexidade:

1. proteção social básica: visa à prevenção de situações de risco por meio de ações voltadas para famílias em situação de vulnerabilidade social, trabalhando suas potencialidades e o fortalecimento dos vínculos familiares e comunitários;

2. proteção social especial: compreende os atendimentos, os serviços de informação, orientação, apoio e atividades de inclusão social visando à garantia e defesa de direito aos indivíduos (crianças, adolescentes, pessoas idosas, pessoas com deficiência, mulheres) e as famílias com direitos violados, adolescentes em cumprimento de medidas socioeducativas em meio aberto - Liberdade Assistida (LA) e a Prestação de Serviço à Comunidade (PSC) - e o atendimento especial, próprio à população em situação de rua. Esses serviços são disponibilizados pela Secretaria de Assistência Social (SEMAS) por intermédio dos Centros de Referência Especializados de Assistência Social (CREAS), na Média Complexidade e com as Unidades de Alta Complexidade, bem como as instituições da rede socioassistencial conveniada;

3. parte integrante da proteção especial: de Média Complexidade, operada por meio do Programa Social Especial (PSE): serviço de apoio, orientação e acompanhamento a famílias com um ou mais de seus membros em situação de ameaça ou violação de direitos. Compreende atenções e orientações direcionadas à promoção de direitos, à preservação e ao fortalecimento de vínculos familiares e comunitários, além do fortalecimento da função de proteção das famílias diante do conjunto de condições que as vulnerabilizam e/ou as submetem a situações de risco pessoal e social. De alta complexidade: oferece apoio a famílias e indivíduos que se encontram em situação de abandono, ameaça ou violação de direitos, necessitando de acolhimento provisório, fora de seu núcleo familiar de origem. Os Centros de Referência Especializados em Assistência Social (CREAS) são locais que ofertam os serviços elencados em epígrafe.

É imperativo um desenho de programa de assistência social em Cuidados Paliativos em oncologia, abarcando os três níveis de proteção social explicitados anteriormente em articulação entre a Secretaria Nacional de Assistência Social (SNAS) (órgão 
responsável pela gestão da Política Nacional de Assistência Social (PNAS) e o Instituto Nacional de Câncer (INCA) (órgão assessor, executor e coordenador da Política Nacional de Atenção Oncológica do Ministério da Saúde).

\section{CONSIDERAÇÕES FINAIS}

Este estudo possui um caráter introdutório, portanto não tem a intenção de esgotar um tema tão complexo. Tem como preocupação axial a reflexão para uma ação transformadora. Trata-se de uma área recente de atuação médica, carregada de tabus e desconhecimento da população em geral. Evidenciam-se no decorrer do texto suas conquistas, dilemas e desafios.

Os Cuidados Paliativos expressam a realidade da saúde pública brasileira: carente e no CTI à espera de salvação. É preciso elaborar leis que, de fato, sejam executadas - a expansão da Rede Nacional de Cuidados Paliativos é uma iniciativa que deveria ser posta em prática.

Compreende-se o campo da saúde como parte integrante da seguridade social e, consequentemente, a gestão social como um conjunto de processos sociais nos quais a ação gerencial se desenvolve por meio de uma ação compartilhada entre os envolvidos, fomentando a participação e o controle social - entendidos como um exercício consciente, voluntário e conquistado Tenório (2007).

Nesta perspectiva, faz-se necessário destacar que, entre os fatores que indicam os desafios e especificidades da gestão pública, estão: a necessária garantia de fluxos sistemáticos de recursos públicos para o atendimento das demandas sociais e, ao mesmo tempo, a potencialização dos resultados; indispensável transparência em suas ações e necessária articulação dos campos social, econômico e político para o estabelecimento de prioridades, impedindo a fragmentação das ações (PEREIRA, 1996; RAICHELIS, 1998).

Assim, entende-se que a política de assistência social implementada em diferentes níveis de proteção social disponibiliza serviços sociais que deveriam incorporar as demandas dos cuidados paliativos, integrando e acolhendo as dificuldades dos cidadãos dependentes das instituições prestadoras de Cuidados Paliativos por meio de dispositivos legais (via convênios, por exemplo).

Arremate-se o texto registrando que o país encontra-se em uma transição jurídica rumo à expansão e consolidação da rede nacional de Cuidados Paliativos, na garantia da existência como um direito, proporcionando uma assistência integral e de qualidade a todos que se encontram fora de possibilidade de cura. 


\section{REFERÊNCIAS}

ACADEMIA NACIONAL DE CUIDADOS PALIATIVOS. In: CARVALHO, R. T. de; PARSONS, H. A. (Org.). Manual de Cuidados Paliativos. 2. ed. Porto Alegre: Sulina, 2012.

ASSOCIACIÓN LATINOAMERICANA DE CUIDADOS PALIATIVOS. Atlas de Cuidados Paliativos en Latinoamérica. Edición cartográfica. Houston: IAHPC Press, 2013.

BAÚ, M. K. Capacidade jurídica e consentimento informado. Revista Bioética e Ética Médica, Brasília, CFM, v. 8, n. 2, p. 285-298, 2000.

BOFF, L. Saber cuidar - ética do humano - compaixão pela terra. Petrópolis: Vozes, 1999.

CAMPOS, G. W. S. Subjetividade e administração de pessoal: considerações sobre modos de gerenciar o trabalho em equipe. In: MERHYR, E. E.; ONOCKO, R. (Org.). Agir em Saúde: um desafio para o público. São Paulo: Hucitec, p. 229-266, 1997.

CAMPOS, G. W. S.; DOMITI, A. C. Apoio matricial e equipe de referência: uma metodologia para gestão do trabalho interdisciplinar em saúde. Cadernos de Saúde Pública, Rio de Janeiro, v. 23, n. 2 , p. 399-407, fev. 2007.

CARVALHO, M. C. B. Gestão Social e Trabalho Social desafios e percursos metodológicos. São Paulo: Cortez, 2014.

CARVALHO, U. C. S. A necessária atenção à família do paciente oncológico. Revista Brasileira de Cancerologia, Rio de Janeiro, INCA, v. 54, n. 1, p. 97-102, 2008.

CENTRO BRASILEIRO DE ESTUDOS DA SAÚDE. Renovar a política preservando o interesse público na saúde. Nov. 2011. Disponível em: <http://cebes.org.br/site/wp-content/uploads/2013/10/35_ Anos_de_Luta_pela_Reforma_Sanitaria-Tese_Política_Cebes.pdf $>$. Acessado em: Acesso em: 23 de abril 2012

CHAUI, M. Uma nova classe trabalhadora. In: SADER, E. (Org.). 10 anos de governos pós-neoliberais. São Paulo: Boitempo, 2013.

COUTINHO, C. N. Notas sobre cidadania e modernidade. Revista Ágora, v. 2, n. 3, 2005.

CSIKAI, E. L.; CHAITIN, E. Ethics in end-of-life decisions in social work practice. Chicago, USA: Lyceum Books, INC, 2006.

DADALTO, L. Testamento Vital. Rio de Janeiro: Lumen Juris Ed., 2010.

DEMO, P. Pobreza política: a pobreza mais intensa da pobreza brasileira. Campinas, São Paulo: Armazém do Ipê (autores associados), 2006.

DESLANDES, S. F. Análise do discurso oficial sobre humanização da assistência hospitalar. Ciência e Saúde Coletiva, v. 9, n. 1, p. 7-13, 2004.

EMANUEL. J.; EMANUEL, L. L. The promise of a good death. Lancet, v. 351, n. Suppl. II, p. 21- 29, 1998.

FALEIROS, V. P. A política social do estado capitalista. 12. ed. São Paulo: Cortez, 2009.

FLORIANI, C. A.; SCHRAMM, F. R. Desafios morais e operacionais da inclusão dos cuidados paliativos na rede de atenção básica. Cad. Saúde Pública, v. 23, n. 9, p. 2072-2080, 2007.

FROSSARD, A. Vidas em partidas. Rio de Janeiro: Quartet editora, 2014.
HÖFLING, E. M. Estado e políticas (públicas) sociais. Cadernos CEDES, Campinas, n. 55, p. 30-41, nov. 2001.

HOWLETT, M.; RAMESH, M. Studying Public Policy. Canadá: Oxford University Press, 1995.

IBGE. Pesquisa nacional por amostra de domicílios. Brasil, 2011. Disponível em: <www.ibge.gov.br/ho,e/estatística/pesquisas/pesquisaresultados.php/id pesquisa=40>. Acessado em: 20 de maio 2012.

INCA. Informe INCA. Ano, 19, n. 331, dezembro 2014.

JANCZURA, R. Risco ou vulnerabilidade social? Revista Textos \& Contextos, Porto Alegre, PUCRS, v. 11, n. 2, p. 301-308, 2012.

KORNIS, G. E. M. A crise do Estado de Bem-Estar: problemas e perspectivas da proteção social. 1994. Tese (Doutorado) - Instituto de Economia Industrial, Universidade Federal do Rio de Janeiro, Rio de Janeiro, 1994.

LAURELL A. C. La logica de la privatización en salud. In: EIBENSCHUTZ, C. (Org.). Política de Saúde: o público e o privado. Rio de Janeiro: Fiocruz, 1996.

LOBATO, L. V. C. Dilemas da institucionalização de políticas sociais em vinte anos de Constituição de 1988. In. FLEURY, S.; LOBATO, L. V. C. (Org.). Seguridade Social, Cidadania e Saúde. Rio de Janeiro: CEBES, 2009.

MARTINS, J. S. Exclusão social e a nova desigualdade. 3. ed. São Paulo: Paulus, 2007.

MENEZES, R. A. Em busca da boa morte: antropologia dos cuidados paliativos. Rio de Janeiro: Fiocruz e Garamond, 2004.

MINAYO, M. C. S. Análise qualitativa: teoria, passos e fidedignidade. Disponível em: <http://www.scielosp.org/pdf/csc/v17n3/v17n3a07>. Acessado em: 29/01/2012.

MINISTÉRIO DA SAÚDE (Brasil). Portaria no 4.279, de 30 de dezembro de 2010. Estabelece diretrizes para a organização da Rede de Atenção à Saúde no âmbito do Sistema Único de Saúde (SUS). Diário Oficial da União, Brasília, DF, no 208, 28 de out. 2011b, seção 1, 44 p.

MINISTÉRIO DA SAÚDE (Brasil). Melhor em casa: A segurança do hospital no conforto do seu lar. Cadernos de Atenção domiciliar. Brasília, 2012. v. 1.

MINISTÉRIO DO DESENVOLVIMENTO SOCIAL E COMBATE À FOME (Brasil). Norma Operacional Básica - NOB/SUAS. Secretaria Nacional de Assistência Social. Brasília, 2005.

MINISTÉRIO DO DESENVOLVIMENTO SOCIAL E COMBATE À FOME SECRETARIA NACIONAL DE ASSISTÊNCIA SOCIAL. POLÍTICA NACIONAL DE ASSISTÊNCIA SOCIAL - PNAS/2004 - NORMA OPERACIONAL BÁSICA - NOB / SUAS. Brasília, 2009.

MINISTÉRIO DO DESENVOLVIMENTO SOCIAL E COMBATE À FOME. NOB/SUAS: Aprimoramento da Gestão e Qualificação dos Serviços Socioassistenciais. Secretaria Nacional de Assistência Social. Brasília, 2010.

NERI, M. A nova classe média - o lado brilhante da base da pirâmide. Rio de Janeiro: Saraiva, 2012. 
NETTO, J. P. Crise do socialismo e ofensiva neoliberal. São Paulo: Cortez, 1993. (Coleção Questões de Nossa Época, n. 20).

NOBRE, M. Choque de democracia: razões da revolta. São Paulo: Selo Breve Companhia, Companhia das Letras, 2013. (Edição E-Book).

OLIVEIRA, S. G. Humanização da assistência: um estudo de caso. Revista de Administração em Saúde, v. 9, n. 35, p. 55-62, abr./jun. 2007.

PEREIRA, P. A. Assistência Social na perspectiva dos direitos: crítica aos padrões dominantes de proteção aos pobres no Brasil. Brasília: Thesaurus, 1996.

PEREIRA, P. A. Política Social: temas \& questões. São Paulo: Cortez, 2008.

POCHMANN, M. Desenvolvimento e perspectivas novas para o Brasil. São Paulo: Cortez, 2010.

POCHMANN, M. Nova classe média? O trabalho na base da pirâmide social brasileira. São Paulo: Boitempo, 2012.

PRESIDÊNCIA DA REPÚBLICA (Brasil). Lei Orgânica de Assistência Social no. 8.743, de 7 de dezembro de 1993, publicada no DOU de 8 de dezembro de 1993.

RAICHELIS, R. Esfera pública e conselhos de assistência social: caminhos da construção democrática. São Paulo: Cortez, 1998.

RAICHELIS, R.; RICO, E. M. Gestão Social: Uma questão em Debate. São Paulo: EDUC, 1999.

RESENDE, G. M. Avaliação de políticas públicas no Brasil: uma análise de seus impactos regionais. v. 1. Rio de Janeiro: Ipea, 2014. Il., mapas.

RUA, Maria das Graças. Políticas Públicas. Florianópolis: Departamento de Ciências da Administração/UFSC, 2009.

SPOSATI, A. Seguridade e inclusão: bases institucionais e financeiras da assistência social no Brasil. In: FLEURY, S.; LOBATO, L. V. C. (Org.). Seguridade Social, Cidadania e Saúde. Rio de Janeiro: CEBES, 2009.
SEILD, E. M. F.; ZANNON, C. M. L. C. Qualidade de vida e saúde: aspectos conceituais e metodológicos. Cad. de Saúde Pública, Rio de Janeiro, v. 20, n. 2, p. 580-8, 2004.

SOUZA, J. Os batalhadores brasileiros: nova classe média ou nova classe trabalhadora? 2. ed. Belo Horizonte: Editora UFMG, 2012.

STUCHI, C. G. A concretização constitucional da assistência social e sua afirmação como direito e política pública. In: STUCHI, C. G.; PAULA, R. F. S. PAZ, R. D. O. (Org.). Assistência Social e Filantropia: cenários contemporâneos. São Paulo: Veras, 2012.

SCHRAMM, F. R. A moralidade da biotecnociência: a bioética da proteção pode dar conta do impacto real e potencial das biotecnologias sobre a vida e/ou a qualidade de vida das pessoas humanas? In: SCHRAMM, F. R. et al. (Org.). Bioética, riscos e proteção. Rio de Janeiro: UFRJ/Fiocruz, 2005.

SCHRAMM, F. R.; KOTTOW, M. Principios bioéticos en salud pública: limitaciones y propuestas. Cad. Saúde Pública, v. 17, n. 4, p. 94956, 2001.

TANEZINI, T. C. Z. Parâmetros teóricos e metodológicos para análise de políticas sociais. Revista Ser Social, Brasília, n. 14, p. 13-44, jan./jun. 2004.

TENÓRIO, F. G.; SARAVIA, E. J. Esforços sobre gestão pública e gestão social. In: MARTINS, P. E. M.; PIERANTI, O. P. (Org.). Estado e gestão pública: visões do Brasil contemporâneo. Rio de Janeiro: FGV, 2007.

TRAVASSOS, C.; MARTINS, M. Uma revisão sobre os conceitos de acesso e utilização de serviços de saúde. Cad. Saúde Pública, Rio de Janeiro, v. 20, n. Sup. 2, p. S190-S198, 2004.

WORLD HEALTH ORGANIZATION (WHO). Definition of palliative care. 2002. Disponível em: www.who.int/cancer/palliative/definition/en/>. Acessado em: 29/01/2012.

Andrea Frossard

Doutora em Serviço Social pela Universidade Federal do Rio de Janeiro (UFRJ); Pós-doutora em Ciências Humanas pela Universidade Federal de Santa Catarina (UFSC). E-mail: afrossard@inca.gov.br 